\title{
The Challenges of Spanish Language Teaching in Multilingual India: A Case Study of Delhi
}

\author{
Dhiraj Kumar Rai ${ }^{*}$
}

\section{${ }^{1}$ Jawaharlal Nebru University, INDIA}

*Corresponding Author: dhirajkrai.jnu@gmail.com

Citation: Rai, D.K. (2017). The Challenges of Spanish Language Teaching in Multilingual India: A Case Study of Delhi. Pedagogical Research, 2(2), 05. https://doi.org/10.20897/pr/80950

Published: December 8, 2017

\begin{abstract}
The multilingual surrounding of Spanish Language Teaching (SLT) in India has presented a unique linguistic principle. This principle relies upon the application of English language instructions (as FL1) to combine several methods for teaching-learning Spanish language (as FL2). However, the effectiveness and appropriateness of this linguistic principle, whereby English language instructions are used for SLT, remain undiagnosed. In fact, the technique of SLT in India needs to take into account the local linguistic or dialectical make-up of the actual or potential learners. As such, the process of Spanish Language acquisition in India as inspired by an exposure to local languages/dialects needs to be creatively explored. Furthermore, the recently increasing entries of specific Spanish words/terms in the Indian 'popular language usage', and their implications for SLT in India require to be sufficiently investigated. This article aims at filling in the above-mentioned lacunae by conducting a case study of the status of Spanish Language Teaching in Delhi. It draws the conclusion that the maximum flexibility in the process of eclectically mixing various pedagogical methods of SLT could go a long way in motivating and benefitting both the teachers as well as the students, thereby enhancing the overall efficiency of SLT in multilingual India.
\end{abstract}

Keywords: Spanish language teaching, multilingualism, Indian local dialects, linguistics

\section{INTRODUCTION}

The arrival of Spanish language in Indian intellectual history is a comparatively recent phenomenon. While Indians had encountered the need to learn English as a foreign language because of their colonial historical background, the requirement to learn other European/Romance/Germanic languages (including Spanish) has gradually emerged with India's adoption of the New Economic Policy (NEP) in 1991 which liberalized the Indian economy, thereby facilitating India's increasing interaction with the Spanish speaking developed and developing world in the post-cold war era. A further impetus to learn Spanish as a foreign language in India has emanated from twofold factors: (i) the rise of India as an 'emerging power' and its political strategy to strike closer alliances with the Spanish speaking emerging powers of Latin America (like Brazil); (ii) the peculiar patterns of demographic transition in the 21 st century which indicate a greater reliance of Global North (including Spain) on Global South (including India) for meeting workforce related needs. The shifts in global politics which emphasize upon the magnifying influence of the countries of the Global South in general and of India in particular, have created a peculiar scenario for Spanish Language Teaching in India.

Unlike Britain, Spain never colonized India. After attaining independence from British colonial rule in 1947, Spain recognized India as a sovereign nation-state. Succeeding the inauguration of diplomatic relations between India and Spain in November 1956, Spain opened a resident Embassy in New Delhi in 1958. The establishment of Spanish Embassy in New Delhi struck the beginning of a sustained Indo-Spanish relationship on the sands of time. Ever since, the relationship between India and Spain has remained cordial. In 2003, Casa de la India was 
founded as a platform for the promotion of Indo-Spanish ties in the field of culture, education, cooperation and enterprise ${ }^{1}$. Casa de la India offers workshops and theoretical-practical courses for the general public in the areas of music, theater, dance, ayurveda, gastronomy and other traditional arts of India. These workshops are taught by specialists from Spain and India in collaboration with the Indian Council of Cultural Relations (ICCR) of the Government of India. The activities of Casa de la India have generated heightening curiosity about not only the Indian culture, but also Spanish as a foreign language.

While the longstanding relationship with Spain has formed a favorable atmosphere for the promotion of Spanish language in India, the adoption of the New Economic Policy (read the policy of liberalisation, privatisation and globalisation) in 1991, which has resulted in India's deepening relationships with not only Spain, but also other Spanish speaking countries of Latin America (especially under the ambit of multilateral forums such as BRICS, IBSA, Unasur, Mercosur and BASIC), have significantly contributed to the popularity of Spanish as a foreign language in India. These ties are likely to further solidify in the light of the rise of India as an emerging power in global politics and the cropping up of specific patterns of demographic transitions across the globe in the 21st century.

The rise of India as an 'emerging power' is manifested in the following two evolving trends in India's interactions in global politics: (i) India intends to enhance its trade, technology and policy ties with other emerging economies of Global South (e.g. Brazil and Spanish speaking Latin American countries) with an objective to provide an alternative to the hegemony of the developed countries of Global North ; (ii) India is interested in fostering new partnerships with developed countries of the Global North (including Spain and other European countries which are increasingly dependent on the developing countries of Global South for work force as their domestic population is marked with the growing size of old/non-working-age people) with a goal to reap the 'demographic dividend'2. In this context, Homi Kharas (2010) argues:

'India is set to reap a demographic dividend. Its labour force should grow by more than 1.7
per cent a year over the next 30 years, while population growth is just over 1.2 per cent. So,
the ratio of working age population to total population is on the upswing. In addition, India
still has a relatively low labour force participation rate of 61 per cent. As the population
becomes more urban, rich and educated, participation rates are likely to rise. Goldman Sachs
forecasts that 500 million people will be added to India's cities by 2039. It notes that 10 of the
world's fastest-growing 30 urban areas are in India. To see the impact of demographics and
urbanisation on labour force participation, look at China, which has a labour force
participation rate of 82 per cent and a labour force of over 800 million, compared with India's
516 million. There is a possibility that higher labour force participation could add another full
percentage point to India's labour force growth over the next 20 years bringing it up to 2.7
per cent.'

Undoubtedly, the peculiar patterns of demographic transition at the current historical juncture are likely to boost the reliance of the developed countries of the Global North (including Spain and other European countries) on the developing countries of the Global South (including India which is going to be the most populous country with the largest working-age youth population by 2030!) for meeting workforce related requirements. In this regard, Laura Benito (2012) comments:

Spanish-speaking regions such as Latin America and Spain are specifically seeking bilateral cooperation with India. This approach is opening a world of opportunities for specific Indian industries such as agriculture, information technology, telecommunications, etc., and is consequently leading to the signing of contracts among India and these regions that are

\footnotetext{
${ }^{1}$ The Indian Council for Cultural Relations, City Council of Valladolid, and the Valladolid University are the main patrons of Casa de la India. For a detailed discussion on the economic, commercial, cultural and academic dimensions of Indo-Spain relationship, see India-Spain Relations, Available at http://www.embassyindia.es/india-spain/bilateral-relations [Accessed 14 September, 2017]

${ }^{2}$ For a detailed discussion on India's deepening ties with the Global South, see Shahi, Deepshikha, 2014. India in the Emerging World Order: A Status Quo Power or a Revisionist Force?, Transnational Institute, Netherlands. Available at http://www.tni.org/sites/www.tni.org/files/shifting_power-india.pdf [Accessed October 31, 2017]

${ }^{3}$ For a detailed discussion, see Kharas, Homi. 2010. The Emerging Middle Class in Developing Countries. OECD Development Centre. Available at http://www.oecd.org/dev/44457738.pdf [Accessed October 31, 2017]
} 
experiencing similar growth. From the food and beverage to the BPO industry, Spanishspeaking workforce is more and more in demand ${ }^{4}$.

India's objective to reap the 'demographic dividend' and to further consolidate its rising status in global politics by creating new employment avenues for its swelling working-age population is largely dependent upon India's accelerating politico-economic relationships with countries of the Global North and Global South. It is, therefore, not difficult to anticipate that these intensifying ties of India with Spanish speaking countries of the Global North (including Spain) and Global South (especially Latin America) have created (and are likely to further create) fresh windows of employment opportunities for Spanish language learners/knowers in India, thereby producing fresh demands for the expansion of the institutional base for Spanish Language Teaching in India. Today, the Indian job market witnesses a very high demand for language experts, especially for experts in European languages like Spanish, French, and German along with some East Asian Languages like Japanese, Korean and Chinese. In response to the steadily rising demand for Spanish language experts in the Indian job market, it is crucial to have a critical study of the linguistic principles adopted for imparting Spanish Language Teaching in India.

The multilingual backdrop of Spanish Language Teaching (SLT) in India has presented a unique linguistic principle. This principle relies upon the application of English language instructions (as FL1) to combine several methods for teaching-learning Spanish language (as FL2). However, the effectiveness and appropriateness of this linguistic principle, whereby English language instructions are used for SLT, remain undiagnosed. The purpose of the present chapter is to diagnose the effectiveness and appropriateness of this linguistic principle. In order to do this, the present article undertakes the empirical methodology for assessing the receptivity of this linguistic principle among Spanish language students and teachers, thereby also providing an elaborative account of the suggestive measures which could be potentially adopted in order to widen the scope and relevance of Spanish Language teaching and learning in India in the coming years. The article is divided into three sections. The first section rationalizes the selection of Delhi as the test-case for this empirical study, thereby also throwing light on the nature of empirical study pursued in this chapter. The second section discusses the findings of this study i.e. the viewpoints of Delhi-based Spanish language teachers and students on several crucial aspects of Spanish teaching-learning techniques. Finally, the third section offers suggestive measures to enhance the efficiency of SLT in India's multicultural set up. The article draws the conclusion that a thoroughgoing elasticity in the process of eclectically combining diverse pedagogical methods could go a long way in inspiring and promoting both the teachers as well as the students of SLT, thereby enhancing the overall efficiency of SLT in multicultural India.

\section{DELHI: THE EVOLVING MULTILINGUAL CAPITAL OF INDIA}

The empirical study, that forms the basis for investigating the linguistic principle of teaching-learning Spanish language in India, has been primarily conducted in Delhi. The choice of Delhi as a test-case for conducting this empirical study is justified in terms of the increasing multilingual landscape of the city. As London has been recognized as the multilingual capital of the world ${ }^{5}$, Delhi has been gradually evolving as the multilingual capital of India (along with Mumbai) (Meganathan, 2015) ${ }^{6}$. India is said to be a socio-linguistic giant and the nerve system of this giant is multilingualism ${ }^{7}$. Indian multilingualism is huge in size, having 1620 mother tongues reduced to 200 languages... With the population of many of minorities larger than European countries' (Annamalai, 2001) ${ }^{8}$. This multilingual character of India is represented by Delhi - the political capital of India, where people from different places with diverse linguistic backgrounds have started to come and settle down.

\footnotetext{
${ }^{4}$ For a more detailed narrative on this issue, see Benito, Laura. March 3, 2012. Globalising India Needs Spanish. The Economic Times. Available at http://articles.economictimes.indiatimes.com/2012-03-03/news/31119463_1_spanish-language-indianindustry-indian-market/2 [Accessed September 14, 2017]

${ }^{5}$ For an elaborate discussion on this issue, see Buncombe, Andrew (28 March, 1999) London: Multilingual Capital of the World, The Independent. Available at http://www.independent.co.uk/news/london-multilingual-capital-of-the-world1083812.html [Accessed June 20, 2017]

${ }^{6}$ Meganathan, Ramanujam (2015) The Linguistic Landscape of New Delhi: A Precursor and a Successor of Language Policy. In Hywel Coleman ed. Multilingualisms and Development: Selected proceedings of the $11^{\text {th }}$ Language \& Development Conference, New Delhi, India, pp. 225-237.

${ }^{7}$ Pai, Pushpa (2005) Multilingualism, Multiculturalism and Education: Case Study of Mumbai City. Available at

http:/ / www.lingref.com/isb/4/141ISB4.PDF [Accessed June 20, 2017]

8 Annamalai, E. 2001. Managing Multilingualism in India - Political and Linguistic Manifestation in Language and Development Series, No. 8.
} 
While the Census of India from 1951-1981 suggested that Delhi was not strictly bilingual or multilingual as approximately $75.3 \%$ of Delhiites spoke Hindi (Pattanayak, 1990) ${ }^{9}$, the process of liberalization, privatization and globalization since the 1990s - which has not only facilitated an influx of foreigners in Delhi (the political capital of India) but also of the non-Delhiite Indians from diverse linguistic regions (read provinces or states in India's federal set up) - in search of professional and educational opportunities - has portrayed a picture of Delhi as the emerging multicultural and multilingual capital of India.

In fact, the concept of 'urban multilingualism' has emerged to look at the contact of various different languages/dialects in urban cities like Delhi and the result of this contact, thereby mapping the language variation and change through interactions and transmissions to different contexts from their origin are reflected in their reception. ${ }^{10}$ Additionally, the 'street languages' and colloquialisms are the interesting outcomes of the new cosmopolitan milieus in urban metropolitan Indian cities like Delhi ${ }^{11}$. In fact, Delhi - the political capital of India - has also become a site for raising political voices in favour of multilingualism as a mode to promote social justice (Mohanty et al., 2009) ${ }^{12}$. Since the multilingual character of Delhi remains a well-established fact, the city has been investigated as a model for empirically studying how the Spanish language students and teachers make use of the English language (as FL1) for learning and teaching Spanish (as FL2).

The empirical study pursued here involves gathering opinions - via questionnaires - of a number of Spanish language teachers and students in Delhi-based IB world schools that have a Spanish curricula (e.g. G.D. Goenka, Pathways); foreign language institutes that impart elementary and advanced training in Spanish language (e.g. Cervantes, Instituto Hispania); and corporate houses (e.g. IBM) that mentor their officials in accordance with the specific professional needs for Spanish language learning. The insights gained through these questionnaires are also combined with the first-hand experience of SLT at various levels - schools, foreign language institutes, corporate houses. However, the opinions gathered through this empirical study and the first-hand impressions of these diverse institutional Spanish teaching-learning environments are strictly qualitative, not quantitative. As such, the information collected through this empirical study claims to be only indicative, not conclusive.

\section{EXPERIENCING SLT IN INDIAN MULTILINGUAL ENVIRONMENT: A STUDY OF DELHI-BASED SCHOOLS, FOREIGN LANGUAGE INSTITUTES AND CORPORATE HOUSES}

Located at various levels of India's multilingual environment, the opinions of Spanish language learners and teachers tend to overlap as well as diverge on various aspects of SLT. There seems to be a complete consensus on the acceptance of Spanish as a popular and interesting foreign language course. While the students in Delhibased world schools mostly view the foundational knowledge of Spanish language as a stepping stone in the direction of getting easy entrance into foreign universities (mainly located in a Spanish-speaking countries) for higher education, most of the teachers at these world schools as well as the students and teachers at foreign language institutes consider the advanced knowledge of Spanish language as a way to grab better employmentopenings in Indian and foreign job markets. By contrast, the officials associated with corporate houses take Spanish language training to enhance their outputs/performances at workplace (especially in scenarios that involve dealing with Spanish-speaking officials/business personnel and so on) in order to increase their salaries or chances of promotions.

While most of the teachers at all levels claim to hold information regarding the aims and objectives of the Spanish language course they teach in the classrooms, they seem to be least bothered about their individual

\footnotetext{
${ }^{9}$ Pattanayak observed that that there were no lack of movements for turning the cities unilingual. Yet, even if the urban centres of India turned toward multilingualism, it could only change the aspirations for multilingualism in India, not its multilingual character. See, Debi Prasanna Pattanayak (1990) Multilingualism in India, Clevedon, Philadelphia: USA, Multilingual Matters Ltd.

${ }^{10}$ However, the interactions and transmissions between Hindi, Tamil, Urdu, Punjabi etc. in a polyglot city such as New Delhi cannot be characterized in the same way as a relationship between a mother tongue and a foreign language. They are only other languages, and the relationship between them can at best be described as that of the relationship between the colours of a rainbow. See, Fann, Fikrun Wa (2009) Multilingualism and Cultural Diversity: Exemplified by Europe and India.

Available at http://www.goethe.de/ges/phi/prj/ffs/the/spr/en4980085.htm [Accessed June 25, 2017]

11 The Academic Conclave 2017 organised at Delhi University on the theme of 'Multilingualism in India' provides a rich insight into this aspect. See https://www.eventshigh.com/detail/delhi/4b5eadc603c6538234fdd536a1e1abf5-the-academicconclave-2017-multilingualism [Accessed June 20, 2017]

12 Ajit Mohanty, Minati Pande, Robert Phillipson and Tove Skutnabb-Kangas (eds.) (2009) Multilingual Education for Social Justice: Globalizing the Local. New Delhi: Orient Blackswan Pvt. Ltd.
} 
identification with those aims and objectives. They feel the institutionalized need to 'mechanically' fulfill those aims and objectives with an intention to retain their jobs as teachers. Even worse, they simply do not realize the importance of explaining those aims and objectives to their students. At many instances, the students complain about the disinterest among teachers to follow the basic structures and guidelines of the prescribed curricula which lead to various other associated problems in implementing the chosen Spanish language courses - for instance, complex course design, difficult evaluation and grading scheme, delayed announcement of results which are incompatible with the academic calendar followed by the Indian schools and universities etc. Even the teachers lament over the particular difficulties in grasping and implementing the IB curricula followed at India-based world schools primarily because they are designed keeping in mind the foreign learning environments which are completely distinct from and insensitive to India's multilingual learning circumstances.

Many teachers report an absence of formal training in classroom Spanish Language teaching. They do admit that the students coming from diverse cultural/linguistic backgrounds do not respond in similar manner to the English language instructions imparted by them in the classrooms while teaching Spanish language. While a few students who are well-versed with English respond quickly, the other who are not so well-versed in English but possess a good command over other local dialects respond rather slowly. However, in the absence of a formal training in SLT, the teachers are left clueless in terms of adopting appropriate teaching techniques so as to make the process of SLT accessible to all in an equitable manner. As such the SLT in India remains insensitive to the need for an exposure to local Indian languages/dialects or English (which is considered to be the popular FL1).

Despite a lack of concern regarding the basic structures and guidelines of the prescribed curricula, most of the teachers and students of Spanish language feel that the prior knowledge of English language, if not other foreign language(s) or local Indian dialect(s), helps in developing a better understanding of Spanish language. For instance, the grammatical and phonetic skills acquired while learning English language (as FL1) acts as an effective 'referential point' in the process of learning Spanish language (as FL2). However, the prior bilingual or multilingual background of teachers and students at times obstruct the process of learning Spanish language as at some occasions the teachers and students end up mixing the vocabularies or the grammatical principles of diverse preknown languages/dialects, thereby facing difficulties in following clear rules for each pre-known foreign or local language. In this situation, the eclectic mix of diverse methods of SLT - namely Grammar-Translation Method, Direct-Natural Method, Audio-Visual Method, Cognitive Method, and Communicative Method - does not prove very useful.

While the usage of Spanish terms/words has eventually acquired a larger space in local Indian vocabulary/language usage, it has not necessarily affected the overall process of learning Spanish language in a positive way. Though the increased popular usage of a few selected Spanish terms and a limited exposure to Spanish culture via Bollywood movies, music etc. has most certainly raised the curiosity about Spanish language and culture among lay Indians; it has not helped much in facilitating a quicker understanding and practice of intricate Spanish language rules. Nevertheless, the Delhi-based Spanish language teachers and learners completely agree that a systematic reading, writing and speaking knowledge of Spanish language can significantly brighten their employment prospects in near future. In fact, most of the adult learners opine that the scope and relevance of Spanish Language Teaching in India is going to widen in the coming years.

\section{THE MEASURES FOR IMPROVING SLT IN INDIA: A MARCH TOWARD ALTERNATIVE PATHWAYS}

A modification in the level of techniques can help to resolve to some extent the existing dilemmas generally related to the teaching of Spanish language through the India-based IB world schools (e.g. G. D. Goenka and Pathways), foreign language institutes, and corporate houses. In one way or another, all areas of the IB must be improved. In order to overcome obstacles in the way of effective application of IB in teaching Spanish, certain corrective measures must be taken. These measures can be discussed and applied at two levels: in the field of education; and at the level of course design. In the field of teaching, the following steps can be taken to improve the effectiveness of teaching the Spanish language through the IB:

First, teachers must undergo an essential training session before formally joining their respective colleges. Teachers should be familiar with the background of learning the languages of students in India. Given the variety of languages / dialects spoken in different parts of the country and previous knowledge of English as a foreign language in most cases, English is taken as a relative language to teach Spanish. Therefore, teachers should know well how to teach Spanish, making judicious use of English as the base language ${ }^{13}$.

\footnotetext{
${ }^{13}$ India has two national languages for central administrative purposes: Hindi and English. Hindi is the national language, official and the main liaison language of India. English is an official language partner. The Constitution of India also officially
} 
Second, the IB guidelines should be modified to ensure that teachers could pay more attention to the actual teaching of the Spanish language rather than following the technical requirements emphasized by the IB. The time consumed in adhering strictly to the technical aspects of teaching and assessment / punctuation must give way to create more space for language learning.

Third, teachers should be trained in such a way that they can create enough interest in students to learn the Spanish language. It is often seen that students enrolled in the ab-initio IB course take it very casually, while students enrolled in the IB Language B course postponed it in classes and act as if the course were a break from their Busy study charge, as they find it easier than other subject groups. This lack of seriousness on the part of the students can be eliminated if the teachers are able to clarify the importance of the language learning in a more systematic way.

Fourth, there should be a separate Department Head for each foreign language taught under the IB scheme and the Department Heads must have experience in their respective language to ensure a fair assessment of the student's performance ${ }^{14}$. Despite the clear division of labor between department heads, coordinators and teachers, one faces the conflict of views, particularly during the assessment of student performance. The HOD (Head of Department), coordinator, and teachers should be flexible enough to accommodate comments, comments from each other so that their disagreement does not adversely affect the student's performance / results.

Fifth, teachers should be directed to use specific textbooks for teaching the Spanish language to facilitate a uniform method and the quality of learning Spanish in all IB international colleges. Although IB has a large number of its own publications on all the subjects it offers, an increase in the number of publications on didactic aspects and the execution of foreign language programs would be greatly appreciated.

In addition to making efforts in the field of teaching, the design of the IB course must be modified to be more successful in the context of the learning environment in India. As IB is considered one of the most expensive curricula, its accessibility in a developing country like India must be increased by reducing the price of the course. In fact, the reduction in course fee would attract more Indian students to opt for IB. In addition, the IB should be more popularized in India. Greater awareness and embrace of IB would automatically lead to its greater acceptance at the university level. Jayshree Periwal, director of an IB and CBSE school called Step by Step said:

The advantages of studying in IB schools are many: students are taught to question teachers at elementary level, teaching methodology is Interactive and most importantly, higher education becomes easier for IB students. However, the part with limitations is that International Baccalaureate (IB) as a curriculum is only gaining recognition among elitist parents who wish to send their children abroad for higher education (Khan, 2011).

Indeed, the IB course taught in colleges in India should be designed according to curricula followed in different colleges of India. This would ensure that students who passed with IB programs will easily adapt to the requirements of higher education institutions in India if they do not meet deadlines in foreign universities, as in many cases (Mathai, 2011). Plus, the timing of the initiation and completion of the IB Diploma program should be in sync with the opening and closing of the Indian universities calendar. The results of the IB must be declared together with the declaration of the results of the CBSE and ICSE councils. Timely reporting of results would allow IB-approved students to seek admission to Indian universities on time.

Besides, the IB rating scheme needs major reform. The methodology of the subjective classification system has to be altered to mitigate the bias of any type at the implementation level. In theory, the IB classification scheme provides all teachers with a clear criterion that they should follow for standardized tests ${ }^{15}$. The reality is very different, the criteria are so vague that they turn out to be useless. For example, to get the highest score from an essay, the rating scheme might say something corresponding to 'the candidate uses the argument in an effective and convincing manner'. To some extent one would admit that someone has an effective argument even if they disagree. However, beyond that point, very few people will agree that the argument is "effective" if they disagree

approves twenty-two regional languages for official purposes. See, English as a National Foreign Language in India. Available at http:/ / www.usingenglish.com/comprehension/9.html [Accessed July 22, 2017]

${ }^{14}$ Up-to-date Cambridge University Press resources for the IB Diploma are based on an unparalleled level of experience. Not only are all IB Diploma teachers with extensive experience, but in order to ensure a true breadth of experience and international understanding, IB has appointed an Advisory Board to guide it with key decisions. Each member of the Advisory Board has in-depth knowledge of the different IB regions, but also knows what teachers want and how IB schools operate. For details, see Our IB Advisory Board. Available at http://education.cambridge.org/media/894272/cambridge-universitypress-ib-advisory-board-meet-our-authors.pdf [Accessed July 22, 2017]

${ }_{15}$ A detailed description of the IB scoring scheme is available at http://freepdfdb.org/pdf/mark-scheme-ib [Accessed July $25,2017]$ 
with themselves. So in the end, the grade could represent to what extent the examiner agreed with the student, not the actual consistency of the arguments presented by the student ${ }^{16}$.

In spite of existing gaps, The Educational Policy Improvement Center (EPIC) announced the results of its report 'International Baccalaureate Standards Development and Alignment Project', which analyzed the adaptation of the standards of the IB Diploma Program and the Knowledge and Skills for University Success (KSUS) collegeready standards. The report found the IB standards "highly alienated by KSUS standards" 17 . In particular, the key cognitive strategies emphasized in the Diploma - the skills of critical thinking, intellectual curiosity and interpretation - were totally alienated from the expectations of university professors. Although the report rightly points out the benefits of IB, modifying certain aspects, maintaining the overall matrix is essential to improve its viability in the context of India.

As for the SLT at foreign language institutes, the teachers need to remain especially careful about the specific aspirations of the students/learners who are more clear about the purpose of learning and applying Spanish language than school students. While the Instituto Cervantes has its own syllabus which establishes the appropriate foundations for the teaching of universal, well-spoken Spanish, while respecting the variety found among the diverse Spanish-speaking communities ${ }^{18}$, it pays more attention to maintain consistency with the levels established by the Common European Framework of Reference for Languages (CEFR) than to devise methods to 'correlate' and 'adjust' the specific multilingual makeup of Indian teachers and learners to the broad levels of CEFR. In fact, a good job is done in this direction by Instituto Hispania which works with the Indian educational institutions to introduce Spanish language as part of their curriculum. It allows the students of a specific program to opt for Spanish language courses that could complement their basic degree and get an additional certification while they study at the institution ${ }^{19}$. Instituto Hispania also trains faculty to teach courses based on the specific needs of learners - general Spanish, business Spanish, tourism Spanish, corporate training, specialized training etc.

While SLT at corporate houses are based on tailored-made Spanish language courses for executives and travellers from business firms at their premises, it is important to design those courses in such a way that even those employees who have no prior knowledge of Spanish language get an opportunity to brush their language skills. The teachers must test the prior language skills/levels (English or other foreign and/or local languages/dialects) of the employees and then set the goals for the Spanish language course to be imparted. The SLT in corporate houses must focus on key terminology, jargon and vernacular used in the particular field of employee's specialization (e.g. automobile, Travel and Tourism, IT, etc.).

\section{CONCLUDING REMARKS}

Though a more or less exposure to English language helps Indian teachers-learners to develop uniform instructions for teaching and learning Spanish language courses in Indian multilingual learning environment - as English more often than not remains the known first foreign language (FL1) in multilingual India (thanks to its prolonged history of British colonial rule) - the effectiveness and appropriateness of method(s) adopted for SLT must be determined on case by case basis. Since the psychological orientation of teachers and students located at different levels of India's multilingual environment - schools, language institutes, and corporate houses - vary considerably, it is significant to accordingly design courses and train faculty before letting them interact with the learners or students of Spanish language in classrooms. It is easy to recognize that no one method is fit for all classrooms or all students situated in a single classroom. The maximum flexibility in the process of eclectically mixing various pedagogical methods of SLT could go a long way in motivating and benefitting both the teachers as well as the students, thereby enhancing the overall efficiency of SLT in multicultural India.

\footnotetext{
16 I Believe - A much needed criticism about the IB Diploma, November 11, 2012. Available at http://miryr.wordpress.com/2012/11/11/ib-diploma/ [Accessed July 25, 2017]

17 Study finds IB Diploma graduates well prepared to succeed in college. Available at http://www.ibo.org/announcements/succeedincollege.cfm [Accessed July 25, 2017]

18 See http://nuevadelhi.cervantes.es/en/spanish_courses/spanish_courses.htm [Accessed July 25, 2017]

${ }^{19}$ See http://www.institutohispania.com/courses-offer.php [Accessed July 25, 2017]
} 


\section{REFERENCES}

Adegun, J.A. and Oyeniyi, P.O. (2010). Sports policy as a source of unity for national development. In F.O. Omotoso, A.A. Agagu and O.A. Abegunde, (eds.), Governance, politics and policies in Nigeria (pp 224-230), Porto Novo: Sonoud'Afrique.

Annamalai, E. (2001). Managing Multilingualism in India - Political and Linguistic Manifestation in Language and Development Series, No. 8.

Benito, L. (3 March 2012). Globalising India Needs Spanish. The Economic Times. [online] Available at: http://articles.economictimes.indiatimes.com/2012-03-03/news/31119463_1_spanish-language-indianindustry-indian-market/2 [Accessed 14 September 2017].

Buncombe, A. (28 March 1999). London: Multilingual Capital of the World, The Independent. [online] Available at: http://www.independent.co.uk/news/london-multilingual-capital-of-the-world-1083812.html [Accessed 20 June 2017].

Fann, F.W. (2009). Multilingualism and Cultural Diversity: Exemplified by Europe and India. [online] Available at: http://www.goethe.de/ges/phi/prj/ffs/the/spr/en4980085.htm [Accessed 25 June 2017].

Kharas, H. (2010). The Emerging Middle Class in Developing Countries. OECD Development Centre. [online] Available at: http://www.oecd.org/dev/44457738.pdf [Accessed 31 October 2017].

Mathai, K. (2 August 2011). Not all Colleges Accept Global School Diploma. The Times of India. [online] Available at: https:/ /timesofindia.indiatimes.com/city/chennai/Not-all-colleges-accept-global-schooldiploma/articleshow/9450574.cms [Accessed 4 December 2017].

Meganathan, R. (2015). The Linguistic Landscape of New Delhi: A Precursor and a Successor of Language Policy. In H. Coleman, (ed.), Multilingualisms and Development: Selected proceedings of the 11th Language \& Development Conference, New Delhi, India, pp. 225-237.

Mohanty, A.K., Panda, M., Phillipson, R. and Skutnabb-Kangas, T. (Eds.) (2009). Multilingual Education for Social Justice: Globalizing the Local. New Delhi: Orient Blackswan Pvt. Ltd.

Pai, P. (2005). Multilingualism, Multiculturalism and Education: Case Study of Mumbai City. [online] Available at: http:/ /www.lingref.com/isb/4/141ISB4.PDF [Accessed 20 June 2017].

Pattanayak, D.P. (1990). Multilingualism in India. Clevedon, Philadelphia, USA: Multilingual Matters Ltd.

Shahi, D. (2014). India in the Emerging World Order: A Status Quo Power or a Revisionist Force?. Transnational Institute, Netherlands. [online] Available at: https://www.tni.org/files/download/shifting_power-india.pdf [Accessed 31 October 2017]. 